\title{
Antitumor activity of mixed heat shock protein/ peptide vaccine and cyclophosphamide plus interleukin-12 in mice sarcoma
}

\author{
Quan-Yi Guo, Mei Yuan", Jiang Peng, Xue-Mei Cui, Ge Song, Xiang Sui, Shi-Bi Lu*
}

\begin{abstract}
Background: The immune factors heat shock protein (HSP)/peptides (HSP/Ps) can induce both adaptive and innate immune responses. Treatment with HSP/Ps in cancer cell-bearing mice and cancer patients revealed antitumor immune activity. We aimed to develop immunotherapy strategies by vaccination with a mixture of HSP/ Ps (mHSP/Ps, HSP60, HSP70, Gp96 and HSP110) enhanced with cyclophosphamide (CY) and interleukin-12 (IL-12).

Methods: We extracted mHSP/Ps from the mouse sarcoma cell line S180 using chromatography. The identity of proteins in this mHSP/Ps was assayed using SDS-PAGE and Western blot analysis with antibodies specific to various HSPs. BALB/C mice bearing S180 cells were vaccinated with $\mathrm{mHSP} / \mathrm{Ps} \times 3$, then were injected intraperitoneally with low-dose CY and subcutaneously with IL-12, $100 \mu \mathrm{g} /$ day, $\times 5$. After vaccination, T lymphocytes in the peripheral blood were analyzed using FACScan and Cytotoxicity (CTL) was analyzed using lactate dehydrogenase assay. ELISPOT assay was used to evaluate interferon $\gamma($ IFN- $\gamma)$, and immune cell infiltration in tumors was examined in the sections of tumor specimen.

Results: In mice vaccinated with enhanced vaccine (mHSP/Ps and CY plus IL-12), 80\% showed tumor regression and long-term survival, and tumor growth inhibition rate was 82.3\% (30 days), all controls died within 40 days. After vaccination, lymphocytes and polymorphonuclear leukocytes infiltrated into the tumors of treated animals, but no leukocytes infiltrated into the tumors of control mice. The proportions of natural killer cells, CD8+, and interferon- $\gamma$-secreting cells were all increased in the immune group, and tumor-specific cytotoxic $T$ lymphocyte activity was increased.
\end{abstract}

Conclusions: In this mice tumor model, vaccination with mHSP/Ps combined with low-dose CY plus IL-12 induced an immunologic response and a marked antitumor response to autologous tumors. The regimen may be a promising therapeutic agent against tumors.

\section{Introduction}

Some of the most abundant proteins in the cell belong to the well-conserved family of proteins known as heat shock proteins (HSPs), or glucose-regulated proteins (GRPs). HSPs are present in all living cells; they can exist in an unbound state or a state bound to specific client proteins. HSPs function as molecular chaperones in numerous processes, such as protein folding, assembly and transport, peptide trafficking, and antigen processing under physiologic and stress conditions [1,2].

\footnotetext{
* Correspondence: dr_myuan@yahoo.com; shibilu301@gmail.com
Institute of Orthopedic Research, General Hospital of the People's Liberation

* Correspondence: dr_myuan@yahoo.com; shibilu301@gmail.com
Institute of Orthopedic Research, General Hospital of the People's Liberation Army, Beijing 100853, China
}

(c) 2011 Guo et al; licensee BioMed Central Ltd. This is an Open Access article distributed under the terms of the Creative Commons Attribution License (http://creativecommons.org/licenses/by/2.0), which permits unrestricted use, distribution, and reproduction in any medium, provided the original work is properly cited. of the first identified HSP subtypes, Gp96, can reject tumors [5]. HSP as a natural adjuvant can elicit in cancer patients a specific and active autoimmune response to a tumor [6]. During tumor formation, HSPs increase and bind to exposed hydrophobic tumor polypeptides. HSP-chaperoned peptides enter antigen-presenting cells through specific receptors and prime $\mathrm{T}$ cells by increasing major histocompatibility complex (MHC) class I and II-mediated antigen presentation [7-9]. The relevance of the peptides associated with HSPs for inducing specific immune responses is demonstrated by numerous studies, and GRP96, HSP70, HSP110 and GRP170 purified from diverse tumors and functioning as tumor vaccines 
have shown to cause tumor regression in animal models [10-13]. The factor is successful in $\mathrm{CD}^{+} \mathrm{T}$ celldependent tumor clearance. The immune recognition does not come from HSPs themselves but from binding to peptides [14]. Some HSPs, such as HSP60 and HSP70, augment natural killer (NK) cell activity, which can also elicit innate immune responses $[15,16]$.

As an alternative to selecting a single antigen for tumor vaccine development, random mutations in cancer cells generate antigens unique to an individual. Purification of chaperone HSP from a cancer is believed to co-purify an antigenic peptide "fingerprint" of the cell of origin [17]. Thus, a vaccine comprising HSP/peptide (HSP/P) complexes derived from a tumor, which would include a full repertoire of patient-specific tumor antigens, obviates the need to identify cytotoxic Tlymphocyte (CTL) epitopes from individual cancers. This advantage extends the use of chaperone-based immunotherapy to cancers for which specific tumor antigens have not yet been characterized [18].

After an extensive study, HSPs were found to augment tumor antigen presentation and NK cell activity leading to tumor lysis. Autologous patient-specific tumor vaccines have been generated by purifying HSP-antigen complexes from tumor specimens and are currently being evaluated in clinical trials. Preliminary clinical trials with Gp96 used as a personalized vaccine for immunotherapy in melanoma, renal, colon, ovarian cancer and non-Hodgkin lymphoma have reported results [19-23]. HSP70 as a vaccine for leukemia was studied in a clinical trial [24]. Although various immunotherapeutic approaches have been examined for the treatment of cancer, no such therapy has entered into the clinical standard of care, and the therapeutic effects was not satisfactory. Several challenges still need to be overcome.

Until now, all clinical trials have used the single subtype of HSPs, Gp96 or HSP70, whereas in a few animal tumor models, the combination of Gp96 and HSP70 has been shown to possess antitumor activity superior to the that of each type alone [25]. These results suggest that the mixture of several HSP subtypes may be more effective in a broad range of tumor models. We used the mixture of HSP/Ps (mHSP/Ps) that include HSP60, HSP70, HSP110 and GRP96 as a vaccine and found an effective prophylactic antitumor effect of the mHSP/Ps in a mouse sarcoma model $[26,27]$. The effect protected against tumor challenge in $50 \%$ of immunized mice, but this strategy for the therapeutic treatment in already established tumors were not satisfactory, so enhancing the therapeutic immunity is needed.

Using cytokines to enhance immune reactivity has been reported both in experimental and clinical trials [28]. Interleukin 12 (IL-12) is still the most important single cytokine in inducing antitumor immunity. In experimental tumor models, recombinant IL-12 has demonstrated marked antitumor effects through mechanisms of both innate and adaptive immunity $[29,30]$. The most unique antitumor activity of IL-12 is its ability to eradicate established tumors [31,32]. However, the significant antitumor activity of IL-12 in these models requires the presence of pre-existing immunity in tumor-bearing hosts [33]. Thus, further improvement of IL-12-based immunotherapy also depends on the combination of vaccine-based modalities to establish pre-existing immunity in tumor-bearing hosts.

When patients are diagnosed with cancer, by definition, the tumor has "escaped" the immune system, having passed the phases of "elimination" and "equilibrium." The generation of immune response against these antigens is likely unproductive in the late stage because of multiple immune tolerance mechanisms such as Treg infiltration in the tumor bed, general immune suppression from immunosuppressive cytokines producing by tumor cells, and downregulation of MHC class I molecules on the tumor cells. Also, myeloid-derived suppressor cells (MDSCs) and tumor-associated macrophages (TAMs) create an immunosuppressive environment that leads to suppression of T-cell responses [34,35]. Thus, multiple immunological "brakes" need to be lifted to augment a productive immune response. Combined immunotherapeutic modalities need to be seriously considered. The use of combination therapy with more than one agent or modality is needed. To overcome the multiple immune tolerance mechanisms, combinations of anticancer drugs and immunotherapy have been shown to enhance tumor immunotherapy [36,37]. Treating mice with low-dose cyclophosphamide $(\mathrm{CY})$ decreased the number of Tregs and enhanced the immunostimulatory and antitumor effects [38-40].

To improve the efficacy of tumor immunotherapy, we used the $\mathrm{mHSP} / \mathrm{P}$ vaccine as an agent to induce preexisting immunity in a tumor-bearing mouse host, and combined with CY plus IL-12 to eradicate established large tumors in a therapeutic antitumor mouse model.

\section{Methods}

\section{Animals and Cell Lines}

6-8 weeks-old female BALB/C mice were obtained from the Military Medical Academy of China (Beijing) and bred in the General Hospital of the People's Liberation Army. The institutional animal care and use committee approved the study protocols. The ascetic mouse S180 sarcoma cell line was obtained from the Military Medical Academy of China. The cell line was maintained by serial passages in the BALB/C mouse peritoneal cavity.

\section{Reagents}

Anti-HSP60, anti-HSP70, anti-HSP110 and anti-Gp96/94 antibodies were obtained from Santa Cruz Biotechnology 
(Santa Cruz, CA, USA). Sephacryl S-200HR, concanavaline A (ConA) and adenosine 5'-diphosphate (ADP) affinity column were obtained from Pharmacia (US). Recombinant murine IL-12 was provided by Dr. K. Tsung at the Stanford School of Medicine. CY was obtained from Heng Ray Pharmaceutical Co. (Jiangsu, China).

\section{HSP/P vaccine}

$\mathrm{mHSP} /$ Ps were isolated from fresh, solid S180 subcutaneous tumors implanted in BALB/C mice. Tumor tissue was homogenized by the use of a homogenizer at $4^{\circ} \mathrm{C}$ in buffer $(30 \mathrm{mM} \mathrm{NaHCO}$, pH 7.1) with freshly added protease inhibitor phenyl-methylsulfonyl fluoride $(0.5 \mathrm{mM})$. The homogenate was centrifuged at $10,000 \mathrm{~g}$ for $30 \mathrm{~min}$ at $4^{\circ} \mathrm{C}$ and the supernatant was then centrifuged at $100,000 \mathrm{~g}$ at $4^{\circ} \mathrm{C}$ for $2 \mathrm{~h}$. The resulting supernatant was dialyzed against $20 \mathrm{mM}$ Tris- $\mathrm{HCl}$ and $150 \mathrm{mM}$ $\mathrm{NaCl}, \mathrm{pH} 7.2$, and then was applied to Sephacryl S-200HR. Bovine serum albumin was used as a molecular indicator in a pilot experiment to map the range of eluted fractions. The tumor supernatant protein was eluted with the same sample loading buffer. The collected fractions of eluted protein underwent SDS-PAGE. The fractions of \#3 to \#6 contained proteins of about 40-200 kDa. The combination of these 4 fractions was used as the mHSP/Ps vaccine. The identity of proteins in this combination was assayed using SDS-PAGE and Western blot analysis with antibodies specific to various HSPs.

\section{In vivo antitumor experiments}

To evaluate the antitumor activity of the mHSP/Ps preparation, mice were divided into 6 groups for treatment ( $\mathrm{n}=10$ mice each): 1) normal saline control, 2) mHSP/ Ps, 3) CY plus IL-12, 4) mHSP/Ps plus IL-12, 5) mHSP/ Ps plus CY, 6) mHSP/Ps plus Cy plus IL-12.

All mice were subcutaneously injected in the back with $5 \times 10^{4} \mathrm{~S} 180$ cells. One day later, groups Groups 2, 4, 5, and 6 mice were vaccinated 3 times at 7 -day intervals with $20 \mu \mathrm{g}$ of mHSP/Ps. Groups 5 and 6 received $2 \mathrm{mg}$ of CY intraperitoneally 1 day after the last vaccination. Groups 4 and 6 mice were subcutaneously injected with IL-12, $100 \mathrm{ng} /$ day, for 5 days, 3 days after a CY injection. Group 3 mice received CY plus IL-12 at the same time as Group 6, but the treatment started on day 16 .

The antitumor effects were evaluated by tumor volume, tumor growth inhibition rates, metastasis rate and overall survival time. Tumor volume was determined by the measurement of the shortest (A) and longest diameter (B) using a caliper once every 3 days. The volume $(\mathrm{V})$ was calculated by the formula $\mathrm{V}=\left(\mathrm{A}^{2} \mathrm{~B} / 2\right)$. Curative survival was considered to occur when the tumor did not regrow or disappeared after more than 3 months. Lungs, liver and brains of dead mice were removed and fixed in formalin, embedded in paraffin, and sectioned at $5 \mu \mathrm{m}$. Hematoxylin \& eosin (H\&E) stained samples were examined under a light microscope (Olympus).

\section{Analysis of immune response}

Treatment of mice for analysis of immune responses was the same as that for immunotherapy. Three days after the combined therapy of mHSP/Ps and CY plus IL-12, all mice were killed, and blood and spleen samples were collected. Mice from various control groups were killed at the same time.

Assay for subgroup of $T$ cells $\mathrm{T}$ lymphocytes in the peripheral blood were analyzed using FACScan (Becton Dickinson); cell staining involved a use of FITC- or phycoerythin-conjugated goat antibodies against mouse CD4+, CD8+ and NK cells (Serotect, UK).

Cytotoxicity assays (CTL) Lactate dehydrogenase assay was used to assess in vitro tumor-specific CTL response to immunization with $\mathrm{mHSP} / \mathrm{Ps}$ or $\mathrm{mHSP} / \mathrm{Ps}$ and $\mathrm{CY}$ plus IL-12. Three days after the final IL-12 administration, splenocytes were isolated by Ficoll-Paque density centrifugation and were used as effector cells after restimulation with ConA and mHSP/Ps in vitro for 4 days. S180 as target cells were seeded in 96-well plates. The lymphocytes were serially diluted and plated in 96-well plates in triplicate with varying $\mathrm{E}: \mathrm{T}$ ratios of 40:1, 20:1 and 5:1. Wells containing only target cells or only lymphocytes with culture medium or $0.5 \%$ Triton X-100 served as spontaneous or maximal release controls. After 4-h incubation at $37^{\circ} \mathrm{C}$ and $5 \% \mathrm{CO}_{2}, 150$-ul supernatant was analyzed in a Well scan at OD $490 \mathrm{~nm}$ (BioRad); the percentage of specific lysis was calculated as follows:

$$
\begin{aligned}
& \% \text { specific lysis }=100 \times(\text { experimental release - } \\
& \text { spontaneous release }) /(\text { maximum release - } \\
& \text { spontaneous release })
\end{aligned}
$$

ELISPOT assay for evaluating interferon $\gamma($ IFN- $\gamma)$ Splenocytes were isolated by Ficoll-Paque density centrifugation. $2 \times 10^{5}$ cells were incubated with ConA $(8 \mu \mathrm{g} /$ $\mathrm{ml})$ or additionally restimulated with $\mathrm{mHSP} / \mathrm{Ps}(10 \mu \mathrm{g} /$ $\mathrm{ml}$ ) for 5 days in 96-well ELISPOT plates coated with antibody to bind murine IFN- $\gamma$. The assays followed the kit manufacturer's instructions (U-CyTech B.V. Holland).

Immune cell infiltration in tumors Tumor tissue was removed after mice were killed, fixed in formalin, embedded in paraffin, and sectioned at $5 \mu \mathrm{m}$. H\&Estained tissues were examined under a light microscope.

\section{Statistical analysis}

All experiments were performed in triplicate, and the data were presented as mean \pm SD. Statistical analysis involved a use of SPSS 13.0 (SPSS Inst., Chicago, IL). Data were shown as means \pm SD. A two-tailed paired 
$t$ test with Welch correction was used for comparison of IFN- $\gamma$ levels of the experimental and control groups. A $\mathrm{P}<0.05$ was considered statistically significant.

\section{Results}

\section{Preparation of $\mathrm{mHSP} / \mathrm{Ps}$}

The combination of 4 protein fractions was eluted from S180 tumor cells. The presence of the various HSPs HSP60, HSP70, Gp96 and HSP110 - in the crude preparation was identified by SDS-PAGE and Western blot analysis (Figure 1). As indicated in SDS-PAGE, there were many bands for proteins other than HSPs in the sample, and components of HSP60, HSP70, Gp96 and HSP110 were identified by Western blot, with their purity of $90 \%$ in total proteins.

\section{Therapeutic antitumor effects of $\mathrm{mHSP} / \mathrm{Ps}$ and $\mathrm{CY}$ plus} IL-12 treatment in mouse sarcoma tumor model All 10 mice treated with saline alone died within 40 days because of tumor burden. Some of these mice had tumor metastases in the lung before death. Vaccination with $\mathrm{mHSP} / \mathrm{Ps}$ alone and $\mathrm{mHSP} / \mathrm{Ps}$ plus IL-12 (starting on day 19) also had no antitumor effects. In mice vaccinated with $\mathrm{mHSP} / \mathrm{Ps}$ plus CY (day 16), 10\% showed eradicated tumors. In mice vaccinated with $\mathrm{CY}$ plus IL-12 (starting on day 16), 30\% showed eradicated tumors. In comparison, in mice vaccinated with $\mathrm{mHSP} / \mathrm{Ps}$ followed by Cy plus IL-12 (starting on day 16), 80\% showed eradicated tumors (Figure 2). The mean survival time, except long-term survival, for groups was as follows: saline control, 35.5 days; $\mathrm{mHSP} / \mathrm{Ps}, 32.4$ days; $\mathrm{mHSP} / \mathrm{Ps}$ plus IL-12, 40.1 days; $\mathrm{mHSP} / \mathrm{Ps}$ plus CY, 37.3 days; $\mathrm{CY}$ plus IL-1, 37.4 days; and $\mathrm{mHSP} / \mathrm{Ps}$ plus $\mathrm{CY}$ plus IL-12:,48 days.

The tumor growth curve of S180 tumors in BALB/C mice after vaccination with $\mathrm{mHSP} / \mathrm{Ps}$ plus CY plus IL-12 was less steep than that for all control groups (Figure 3), so tumor progression was inhibited substantially.

To determine whether this antitumor activity induced long-term immunity against tumors, we challenged mice that survived with $5 \times 10^{4} \mathrm{~S} 180$ cells 15 months after the first challenge with the same cell line. No tumors developed in any mice, which indicated that long-term immunological memory against the S180 tumor was associated with tumor eradication by our immunotherapy.

$m H S P / P s$ and $m H S P / P s$ plus $C Y$ plus IL-12 induce immune reaction

Change of immune cell population with various vaccinations In naïve mice, the mean proportion of CD8+ cells in total mononuclear cells was $5.89 \pm 0.36 \%$. At the late stage of tumor-bearing (day 26), the proportion of CD8+ T cells was suppressed to $1.26 \%$. Treatment with $\mathrm{mHSP} / \mathrm{Ps}$ increased the proportion of CD8+ T cells to $9.15 \%$ at about the same time of tumor establishment
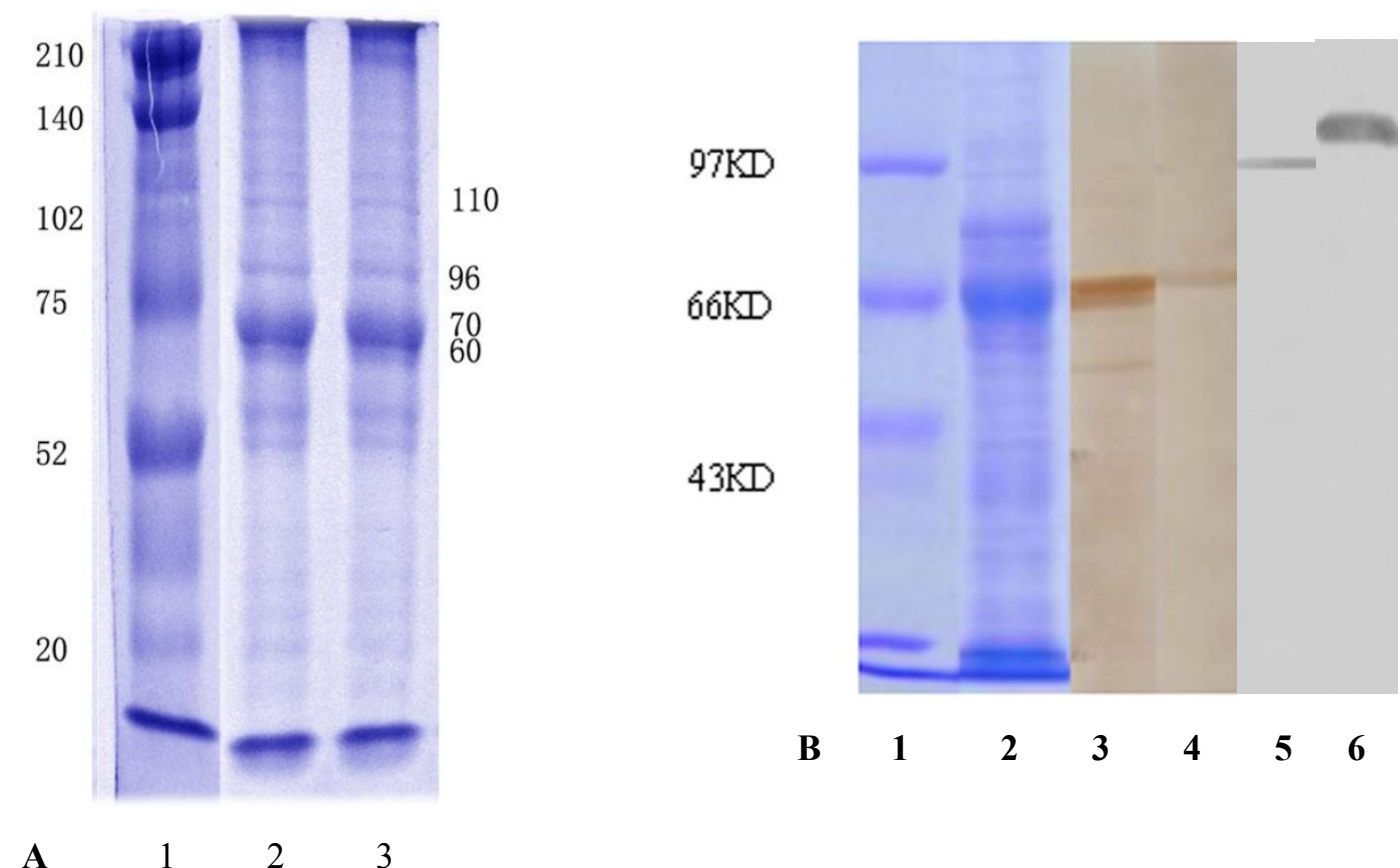

Figure 1 SDS-PAGE and western blot analysis of mixed HSP/Ps from S180 sarcoma. A. SDS-PAGE of mHSP/P from S180; Lane1, molecular standard, Line2,3 collection of F3-F6 from Sephacryl S-200HR. There were many protein bands other than MW60, 70, 96 and110. B. Western blot: Lane 1, SDS-PAGE, molecular standard. 2, SDS-PAGE, collection of F3-F6, Line3 analysis with antibodies against HSP60, Line4 analysis with antibodies against HSP70, Line5 analysis with antibodies against Gp96, and Line6 analysis with antibodies against HSP110. Identified The mixture included HSP60, HSP70, Gp96 and HSP110. 


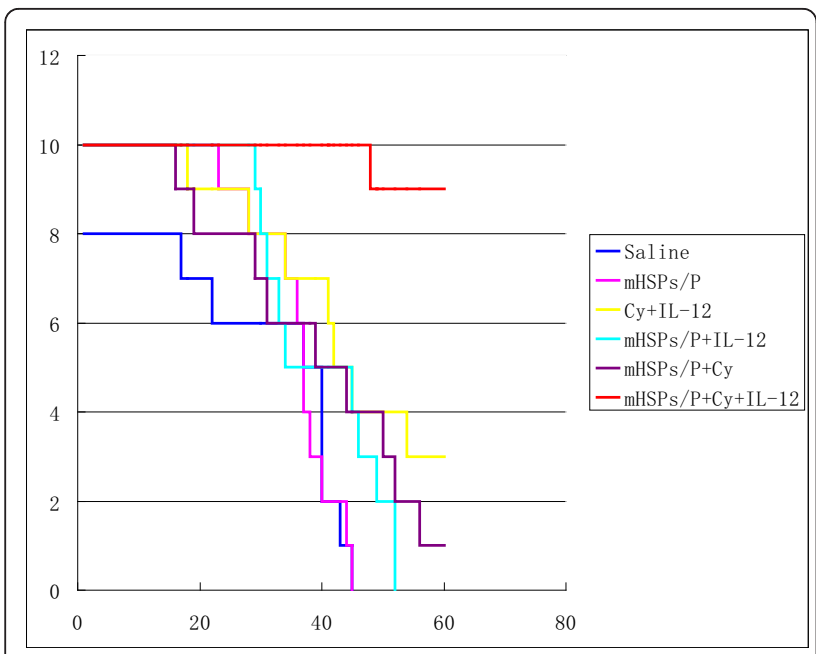

Figure 2 Effect of various $\mathrm{mHSP} / \mathrm{P}$ vaccinations on the survival of S180 tumor-bearing mice. * The number of mouse in each group is 10 .

(day 26), With mHSP/Ps plus CY plus IL-12 treatment, the CD8+ population was higher $(9.21 \pm 1.45 \%)$ than that in $\mathrm{mHSP} / \mathrm{P}$-treated mice and untreated tumor-bearing mice. Similar to the proportion of CD8+ T cells, that of $\mathrm{CD} 4+\mathrm{T}$ cells was suppressed in late-stage tumor-bearing mice. Treatment with $\mathrm{mHSP} / \mathrm{Ps}$ plus $\mathrm{CY}$ plus IL-12 increased the ratio of CD4+ T cells. In mice treated with normal saline, the mean NK cell in total mononuclear cells was $1.70 \% \pm 0.32 \%$. Again, in tumorbearing mice, the ratio of NK cells was suppressed to $0.19 \%$. This ratio was increased to $4.98 \%$ with $\mathrm{mHSP} / \mathrm{Ps}$ alone and was even greater with $\mathrm{mHSP} / \mathrm{Ps}$ plus $\mathrm{CY}$ plus IL-12 (5.72\%).

Number of INF-y-secreting cells was elevated with mHSP/Ps and CY plus IL-12 vaccination To determine whether vaccination with $\mathrm{mHSP} / \mathrm{Ps}$ results in increased number of antigen-specific Th1 cells and IFN$\gamma$-producing NK cells, the number of IFN- $\gamma$-secreting splenocytes was determined by an in vitro assay of IFNgamma ELISPOT. The frequency of IFN- $\gamma$-producing splenocytes increased with ConA alone or ConA plus mHSP/Ps in vitro (Figure 4). Under both stimulation conditions, splenocytes from mice treated with both $\mathrm{mHSP} / \mathrm{Ps}$ alone and $\mathrm{mHSP} / \mathrm{Ps}$ plus CY plus IL-12 showed an increased number of IFN-gamma-producing cells, with the later treatment giving the higher number. The number of IFN- $\gamma$ elicited by $\mathrm{mHSP} / \mathrm{P}+\mathrm{Cy}+\mathrm{IL} 12$ vaccination was significantly higher than that of tumor bearing mice and naïve mice, $\mathrm{P}<0.05$.

CTLs generated by mHSP/Ps plus CY plus IL12 are capable of killing target cells To assess the functional effector properties of CTLs generated by mHSP/Ps plus CY plus IL-12, we performed in vitro cytotoxicity assays of lymphocytes isolated from mice treated with $\mathrm{mHSP} / \mathrm{Ps}$ plus CY plus IL-12. The cytolytic activity of effector cells was measured by lactate dehydrogenase assay. Target cells (S180) pulsed with effector splenocyte cells from mice treated with $\mathrm{mHSP} / \mathrm{Ps}$ were killed to some extent by CTLs, an amount higher than in those pulsed with splenocytes from naive mice or tumor-bearing mice not treated with $\mathrm{mHSP} /$ Ps (Figure 5). The cytolysis percentage of $\mathrm{mHSP} / \mathrm{P}+\mathrm{Cy}$ + IL12 vaccine was significantly higher than that of $\mathrm{mHSP} /$ Ps vaccine and naïve mice, $\mathrm{P}<0.05$, and that of tumor bearing mice, $\mathrm{P}<0.01$. In addition, the proportion of lysis of lymphocytes to rabbit liver cancer cells vx2 was very low, $4 \%$ in $\mathrm{E} / \mathrm{T}=5$ and $10 \%$ in $\mathrm{E} / \mathrm{T}=20$.

Lymphocytes and leukocytes were recruited to tumor lesions In histological examination of tumor lesions of immunized mice, leukocytes were found to have infiltrated tumor lesions since numerous lymphocytes were collected in blood vessels and near blood vessel walls, whereas no leukocytes were found to have infiltrated tumors of mice without vaccine (Figure 6). This result showed that pre-immunization was induced after $\mathrm{mHSP} / \mathrm{Ps}$ immunization.

\section{Discussion}

Vaccination with HSP/Ps is personalized, delivering tumor antigen as a fingerprint genome. The vaccine is polyvalence. Here we developed a vaccine with a mixture of $\mathrm{HSP} / \mathrm{Ps}$ which, in addition to HSP70 or Gp96, also included HSp60 and HSP110. The antitumor effects of this mHSP/Ps vaccine were more potent than those of HSP70 or HSP60 alone and of tumor lysates used as vaccine in prophylactic immunization, Table 1. [25]. When using this $\mathrm{mHSP} / \mathrm{P}$ vaccine in mice after tumor transplantation (therapeutic immunization), the antitumor action was not effective, as we showed in this study. The efficacy of therapeutic immunization was effective only in the combination therapy that used immunotherapeutic $\mathrm{mHSP} / \mathrm{Ps}$ combined with CY and IL-12.

For specific immunotherapy, the identical MHC genetic molecules are important, We had no information about the MHC genetic molecules of S180 or MCA-207 when we selected the mouse sarcoma cell lines S180 and MCA-207 as models. However, from reported experimental information and our experiments, we knew that the S180 sarcoma cell lines can grow both in BALB/C and C57 mice, as in our control group, in which all the S180 tumors grew and were not rejected. This finding suggests S180 and BALB/C mice have the matched MHC locus even in allogenic transplantation. The MCA-207 only grew in C57 mice but was rejected in BALB/C mice, and this result suggests that the $\mathrm{MHC}$ of MCA-207 matched only with the MHC of C57 mice; therefore, in our animal models, the allogenic immune 

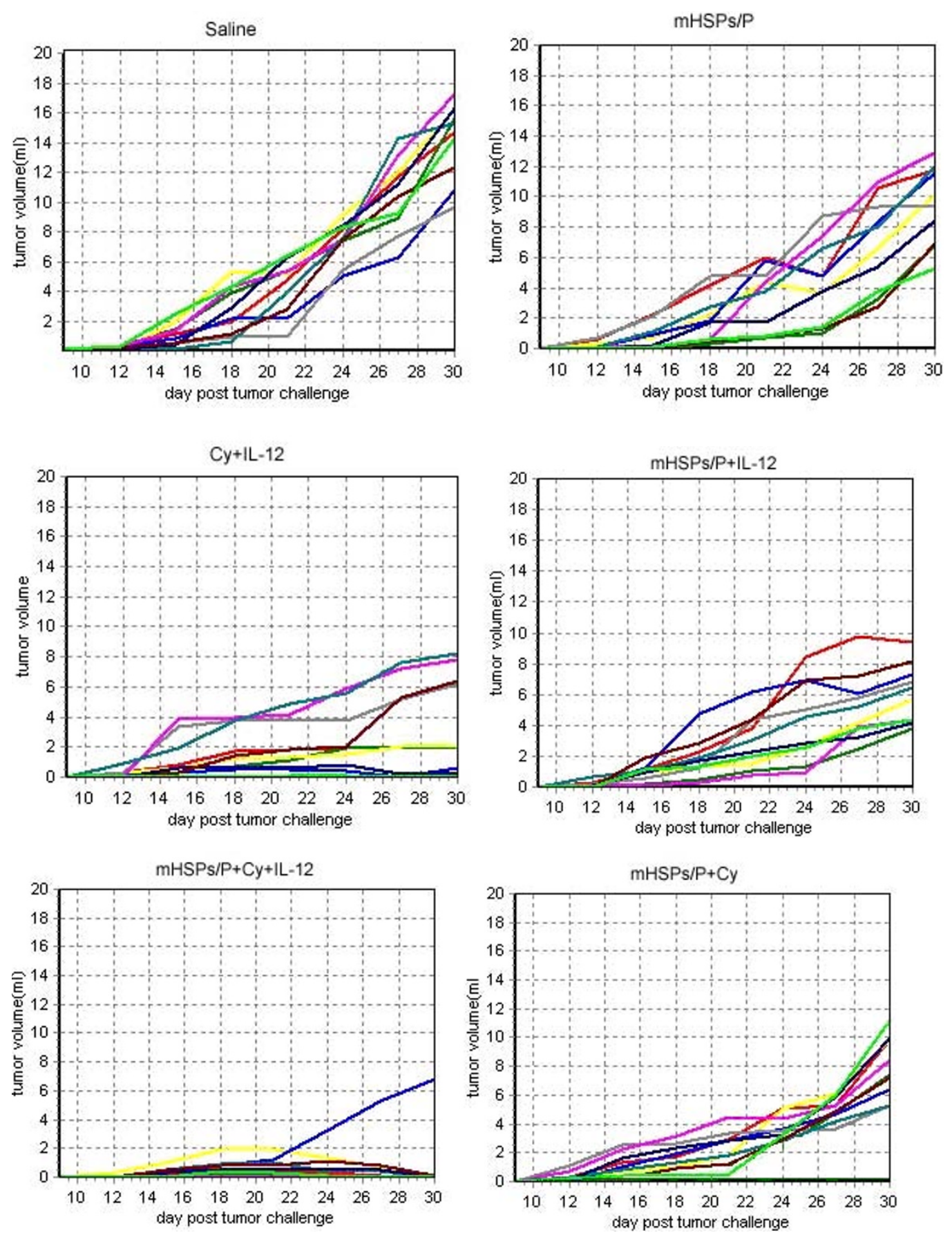

Figure 3 Tumor growth curve of S180 tumor in BALB/C mice after various treatments.

rejection did not occur, and the results of $\mathrm{mHSP} / \mathrm{P}$ antitumor effects were not related to unmatched MHC.

To identify the specificity of $\mathrm{mHSP} / \mathrm{P}$ vaccine, we compared the cytolysis ratio of mHSP/Ps isolated from liver and muscle of naïve mice in vitro and saw no cytolytic effect against S180 sarcoma. The cytolysis ratio was lower than 1\%. Also, we compared the mHSP/p of S180 against rabbit liver cancer cell line vx2, and the cytolysis effect was lower than $10 \%$, [data not shown]. In addition, we found that the mice vaccinated with $\mathrm{mHSP} / \mathrm{P}$ of MCA207 were protected only against MCA207 but not S180 in vivo. Thus, the mHSP/P-induced immune reaction may be autologous tumor-specific, like individual vaccines. 


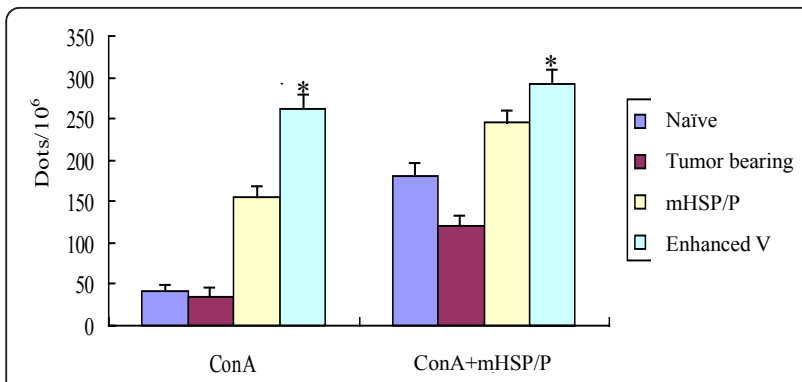

Figure $4 \mathrm{mHSP} / \mathrm{P}+\mathrm{Cy}+\mathrm{IL} 12$ vaccination elicits IFN- $\gamma$ by ELISPOT assay ConA: stimulate lymphocyte proliferation in vitro with ConA. ConA+mHSP/P: stimulate lymphocyte proliferation in vitro with ConA and mHSP/P. IFN- $\gamma$ elicited by $\mathrm{mHSP} / \mathrm{P}+\mathrm{Cy}+\mathrm{IL} 12$ vaccination is significantly higher than tumor bearing mice and naïve mice, ${ }^{*} P<0.05$.

IL-12 is highly effective against established immunogenic tumors. In our study, the combination of IL-12 and Cy eradicated tumors in $30 \%$ of mice, and in IL-12-treated mice, all tumor mass necrosis and an ulcer formed before tumor eradication, suggesting the anti-angiogenesis activity of IL-12 was involved [41], When we combined mHSP/Ps with CY and IL-12 to enhance the immunization efficacy, the antitumor efficacy enhanced. However, with $\mathrm{mHSP} / \mathrm{Ps}$ and $\mathrm{CY}$ alone or with $\mathrm{mHSP} / \mathrm{Ps}$ and IL-12 alone, the antitumor efficacy was not improved. Our results suggested that one potential mechanism of mHSP/Ps and CY plus IL-12 in augmenting therapeutic immunotherapy strategies was that mHSP/P immunization activated the antitumor immunization, and at the same time, also induced the T-cell tolerance directed toward tumor-associated antigens and limited the repertoire of functional tumor-reactive $\mathrm{T}$ cells. Therefore, the ability of vaccines to elicit effective antitumor immunity was impaired. CY has immunomodulatory effects, and low-dose CY (20 mg/kg) was found

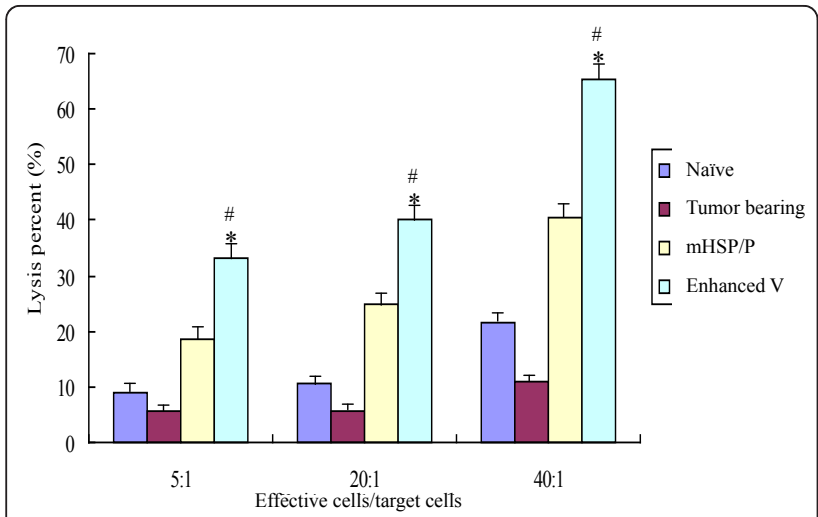

Figure $5 \mathrm{mHSP} / \mathrm{P}+\mathrm{Cy}+\mathrm{IL} 12$ vaccination elicits a tumor-specific $\mathrm{CTL}$ response. The cytolysis percent of $\mathrm{mHSP} / \mathrm{P}+\mathrm{Cy}+\mathrm{IL} 12$ vaccine is significantly higher than $\mathrm{mHSP} / \mathrm{P}$ vaccine and naïve mice ${ }^{*} \mathrm{P}<0.05$, and tumor bearing mice, $\# P<0.01$.

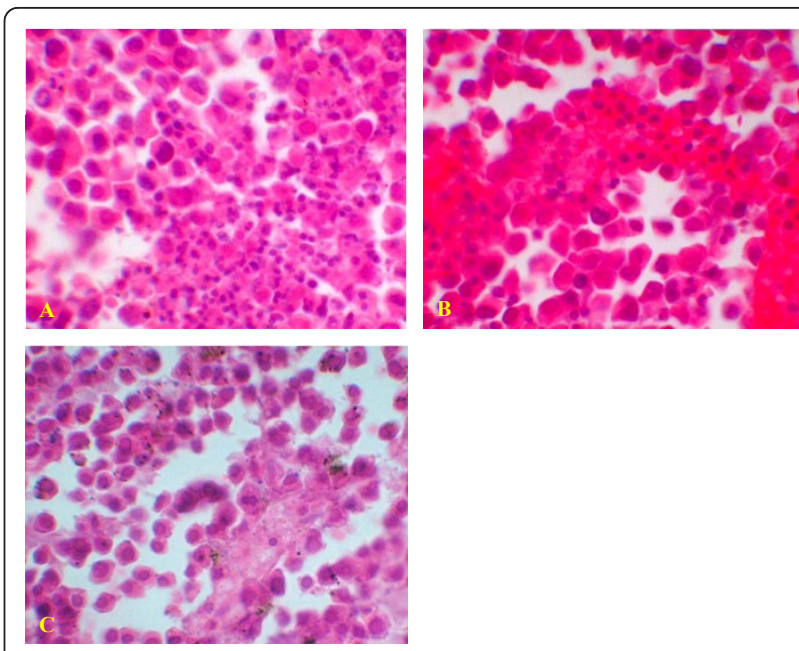

Figure 6 Lymphocytes infiltration in tumor of mHSP/P immunized mice. A leukocytes infiltration into tumor lesion after mHSP/P immunization, X40. B lymphocytes in blood vessels after mHSP/P immunization, X40. C No lymphocytes infiltration in tumor lesion after NS treatment, $\mathrm{X} 40$. Which revolved preimmunization after $\mathrm{mHSP} / \mathrm{P}$ immunization.

to selectively deplete CD4+CD25+ T cells (Treg) and impede the tolerance [42]. CY can preconditioning enhance the CD8+ T-cell response to peptide vaccination, thus leading to enhanced antitumor effects against pre-existing tumors [43]. Cy markedly enhanced the magnitude of secondary but not primary CTL response induced by vaccines and synergized with vaccine in therapy but not in prophylaxis tumor models [44].

With our enhanced vaccine, IFN- $\gamma$ secretion was significantly increased. In addition, CD8+ and NK cells were triggered to release IFN $-\gamma$ and mediate cytotoxic activity. The increased IFN- $\gamma$ secretion may also be due to the combined effects of HSP60 in $\mathrm{mHSP} / \mathrm{P}$ and IL12. Hsp60-inducing IFN- $\gamma$ depends strictly on the ability of the macrophages to produce IL-12 [45].

Activation and expansion of tumor-specific $\mathrm{T}$ cells by HSP/Ps were identified [46]. Our study showed that mHSP/Ps purified from S180 sarcoma cells activated tumor antigen-specific $\mathrm{T}$ cells in vitro, and the induction of tumor-specific CTLs with enhanced vaccine was stronger than that with $\mathrm{mHSP} / \mathrm{Ps}$ alone, possibly because of the combined effect of HSP60 and IL-12. HSP60 induces a strong non-specific immune reaction, but when it meets IL-12, it can activate cytotoxic T cells. HSP60 can mediate the activation of cytotoxic T cells, which depends on production of IL-12 [47].

Our data showed that inflammatory cells infiltrated tumors with $\mathrm{mHSP} / \mathrm{P}$ vaccination and that a preexisting antitumor immune response was elicited, which was required for an effective IL-12 response for tumor rejection. 
Table 1 Comparison of antitumor effects of various HSPs

\begin{tabular}{lccccc}
\hline & Untreated & mHSP/p & HSP70 & HSP60 & tumor lysate \\
\hline No. of animals tested & 10 & 10 & 10 & 10 & 10 \\
Complete regression, no. (\%) & 0 & $4(40 \%)$ & $3(33.3 \%)$ & $1(10 \%)$ & $2(20 \%)$ \\
Tumor growth inhibition rate (\%) & & 82.3 & 62.3 & 42.6 & 66.2 \\
\hline
\end{tabular}

\section{Conclusions}

To enhance the current immunotherapeutic efficacy, novel strategies designed in the laboratory and proven in preclinical animal tumor models are now entering the clinic trials $[48,49]$. These novel strategies involved breaking tolerance to tumor self-antigens by inhibiting regulatory $\mathrm{T}$ cells, boosting $\mathrm{T}$-cell co-stimulation and using combinations of recombinant cytokines and other defined molecules with "immuno-enhancing" activities. Our immunization protocol of a combination immunotherapeutic regimen of vaccination with $\mathrm{mHSP} / \mathrm{Ps}$ followed by low-dose CY plus IL-12 resulted in enhanced immunologic antitumor activity that was better than that of either treatment alone.

\section{Acknowledgements and Funding}

This study was supported by the National High Technique Research and Development Program of China funded by the Chinese government (863 No. 2007AA021806).

We are thankful of Dr. Kangla Zong at the Stanford University Medical Center, Dept. Surgery, for his great assistance in the concept and design of this study. We are thankful of Dr. Kevin Lee at UCLA School of Dentistry for his language corrections in this manuscript.

\section{Authors' contributions}

Q-YG The design of the study. MY Conceived and the design of the study, drafted the manuscript. JP Carried out the animal study and performed the statistical analysis. X-MC Preparation the HSP/P vaccine, carried out the immunoassays. GS Carried out the immunoassays. XS Carried out the animal study and the immunoassays. S-BL Conceived of the study. All authors read and approved the final manuscript.

\section{Competing interests}

The authors declare that they have no competing interests.

Received: 23 November 2010 Accepted: 26 February 2011

Published: 26 February 2011

\section{References}

1. Lindquist S, Craig EA: The heat-shock proteins. Annu Rev Genet 1988, 22:631-677.

2. Clarke AR: Molecular chaperones in protein folding and translocation. Curr Opin Struct Biol 1996, 6:43-50.

3. Giaginis C, Daskalopoulou SS, Vgenopoulou S, Sfiniadakis I, Kouraklis G, Theocharis SE: Heat Shock Protein-27, -60 and -90 expression in gastric cancer: association with clinicopathological variables and patient survival. BMC Gastroenterology 2009, 9:14-14

4. Ogata M, Naito Z, Tanaka S, Moriyama Y, Asano G: Overexpression and localization of heat shock proteins mRNA in pancreatic carcinoma. J Nippon Med Sch 2000, 67(3):177-185.

5. Srivastava PK, Deleo AB, Old LJ: Tumor rejection antigens of chemically induced sarcomas of inbred mice. Proc Natl Acad Sci USA 1986, 83:3407-3411.

6. Rivoltini L, Castelli C, Carrabba M, Mazzaferro V, Pilla L, Huber V, Coppa J, Gallino G, Scheibenbogen C, Squarcina P, Cova A, Camerini R, Lewis J, Srivastava PK, Parmiani G: Human tumor-derived heat shock protein 96 mediates in vitro activation and in vivo expansion of melanoma- and colon carcinoma-specific T cells. J Immunol 2003, 171(7):3467-74.

7. Janetzki S, Blachere NE, Srivastava PK: Generation of tumor-specific cytotoxic T lymphocytes and memory $T$ cells by immunization with tumor-derived heat shock protein gp96. J Immuno 1998, 21(4):269-276.

8. Singh-Jasuja H, Scherer HU, Hilf N, Arnold-Schild D, Rammensee HG, Toes RE, Schild $\mathrm{H}$ : The heat shock protein gp96 induces maturation of dendritic cells and down-regulation of its receptor. Eur J Immunol 2000, 30:2211-2215.

9. IChu NR, Wu HB, Wu TC, Boux L, Mizzen LA, Siegel M: Immunotherapy of a human papillomavirus(HPV) type 16 E7-expressing tumor by administration of fusion HPV16 E7. Clin Exp Immunol 2000, 121:216-225.

10. Ciupitu Anne-Marie T, Petersson M, Kono K, Charo J, Kiessling R: Imunization with heat shock protein 70 from methylcholanthreneinduced sarcomas induces tumor protection correlating with in vitro T cell responses. Cancer Immuno Immunother 2002, 51:163-170.

11. Tamura Y, Peng P, Liu K, Daou M, Srivastava PK: Immunotherapy of tumor with autologous tumor derived heat shock protein preparations. Science 1997, 278(3):116-120.

12. Wang XY, manjili MH, Park J, Chen X, Repasky E, Subjeck JR: Development of cancer vaccines using autologous and recombinant high molecular weight stress proteins. Methods 2004, 32:13-20.

13. Segal $B H$, Wang $X-Y$, Dennis CG, Youn $R$, Repasky EA, Manjili MH, Subjeck JR: Heat shock proteins as vaccine adjuvants in infections and cancer. Drug Discovery Today 2006, 11(11-12):515-519.

14. Gullo CA, Teoh G: Heat shock proteins: to present or not, that is the question. Immunology Letters 2004, 9491-2:1-10.

15. Gastpar R, Gehrmann M, Bausero MA, Asea A, Gross C, Schroeder JA, Multhoff G: Heat shock protein 70 surface-positive tumor exosomes stimulate migratory and cytolytic activity of natural killer cells. Cancer Res 2005, 65:5238-5247.

16. Pilla L, Squarcina P, Coppa J, Mazzaferro V, Huber V, Pende D, Maccalli C, Sovena G, Mariani L, Castelli C, Parmiani G, Rivoltini L: Natural killer and NK-Like T-cell activation in colorectal carcinoma patients treated with autologous tumor-derived heat shock protein 96. Cancer Res 2005, 65:3942-3949.

17. Srivastava : Roles of heat-shock proteins in innate and adaptive immunity. Nat Rev Immunol 2002, 2:185-194.

18. Hoos Axel, Levey Daniel L: Vaccination with heat shock protein-peptide complexes: from basic science to clinical applications. Expert Review of Vaccines 2003, 2(3):369-379.

19. Testori A, Richards J, Whitman E, Mann GB, Lutzky J, Camacho L, Parmiani G, Tosti G, Kirkwood JM, Hoos A, Yuh L, Gupta R, Srivastava PK, C100-21 Study Group: Phase III comparison of vitespen, an autologous tumor-derived heat shock protein gp96 peptide complex vaccine, with physician's choice of treatment for stage IV melanoma: the C-100-21 Study Group. J Clin Oncol 2008, 26(6):955-62.

20. Eton O, Ross Merrick I, East MJ, Mansfield PF, Papadopoulos N, Ellerhorst JA, Bedikian AY, Lee JE: Autologous tumor-derived heat-shock protein peptide complex-96 (HSPPC-96) in patients with metastatic melanoma. Journal of Translational Medicine 2010, 8:9.

21. Wood C, Srivastava P, Bukowski R, Lacombe L, Gorelov Al, Gorelov S, Mulders P, Zielinski H, Hoos A, Teofilovici F, Isakov L, Flanigan R, Figlin R, Gupta R, Escudier B, the C-100-12 RCC Study Group: An adjuvant autologous therapeutic vaccine (HSPPC-96; vitespen) versus observation alone for patients at high risk of recurrence after nephrectomy for renal cell carcinoma: a multicentre, open-label, randomised phase III trial. Lancet 2008, 372(9633):145-154.

22. Mazzaferro V, Coppa J, Carrabba MG, Rivoltini L, Schiavo M, Regalia E, Mariani L, Camerini T, Marchianò A, Andreola S, Camerini R, Corsi M, Lewis JJ, Srivastava PK, Parmiani G: Vaccination with autologous tumor- 
derived heat-shock protein gp96 after liver resection for metastatic colorectal cancer. Clin Cancer Res 2003, 9:3235-3245.

23. Oki Y, McLaughlin P, Fayad LE, Pro B, Mansfield PF, Clayman GL, Medeiros L, Kwak LW, Srivastava PK, Younes A: Experience with heat shock protein-peptide complex 96 vaccine therapy in patients with indolent non-Hodgkin lymphoma. Cancer 2007, 109(1):77-83.

24. Gong J, Zhang Y, Durfee J, Weng D, Liu C, Koido S, Song B, Apostolopoulos V, Calderwood SK: A Heat Shock Protein 70-Based Vaccine with Enhanced Immunogenicity for Clinical Use. J Immunology 2010, 184(1):488-96.

25. Graner M, Raymond A: Tumor-derived multiple chaperone enrichment by free-solution isoelectric focusing yields potent antitumor vaccines. Cancer Immunol Immunother 2000, 49:476-484

26. Tang Yu, Cui XM, Yuan M, Lu SB: Primary experimental observation on mice sarcoma with heat shock protein/peptides complex for immunotherapy. Chin J Cancer Prev Treat 2006, 13(9):648-650

27. Cui XM, Yuan M, Tang Y, Lu SB: Therapeutic effects of mixed heat shock protein/peptides on mice sarcoma. ZhongHua ShiYan Waike ZaZhi 2006, 23(5):636.

28. Pilla L, Patuzzo R, Rivoltini L, Maio M, Pennacchioli E, Lamaj E, Maurichi A, Massarut S, Marchianò A, Santantonio C, Tosi D, Arienti F, Cova A Sovena G, Piris A, Nonaka D, Bersani I, Di Florio A, Luigi M, Srivastava PK, Hoos A, Santinami M, Parmiani G: A phase II trial of vaccination with autologous, tumor-derived heat-shock protein peptide complexes gp96, in combination with GM-CSF and interferon-alpha in metastatic melanoma patients. Cancer Immunol Immunother 2006, 55:958-968.

29. Tsung KL, Dolan JP, Tsung LY, et al: Macrophages as effective cells in interleukine 12 induced T cell-dependent tumor rejection. Cancer Res 2002, 62:5069-5075.

30. Colombo MP, Trinchieri G: Interleukin-12 in anti-tumor immunity and immunotherapy. Cytokine \& Growth Factor Reviews 2002, 13(2):155-168.

31. Gao J-Q, Sugita T, Kanagawa N, lida K, Eto Y, Motomura Y, Mizuguchi H, Tsutsumi Y, Hayakawa T, Mayumi T, Nakagawa S: A single intratumoral injection of a fiber-mutant adenoviral vector encoding interleukin 12 induces remarkable anti-tumor and anti-metastatic activity in mice with Meth-A fibrosarcoma. Biochemical and Biophysical Research Communications 2005, 328(4):1043-1050.

32. Wigginton JM, Gruys E, Geiselhart L, Subleski J, Komschlies KL, Park Jong-W, Wiltrout TA, Nagashima K, Back TC, Wiltrout RH: IFN- $\gamma$ and Fas/FasL are required for the antitumor and antiangiogenic effects of IL-12/pulse IL-2 therapy. J Clin Invest 2001, 108(1):51-62.

33. Hop N Le, Natalie C Lee, Kangla Tsung, Jeffrey A Norton: Pre-Existing Tumor-Sensitized T Cells are essential for Eradication of Established Tumors by IL-12 and Cyclophosphamide Plus IL-12. Journal of Immunology 2001, 167:6765-6772.

34. Nagaraj S, Gabrilovich DI: Tumor escape mechanism governed by myeloid-derived suppressor cells. Cancer Res 2008, 68:2561-2563.

35. Sica A, Bronte V: Altered macrophage differentiation and immune dysfunction in tumor development. J Clin Invest 2007, 117:1155-1166

36. Younes A, Pro B, Robertson MJ, Flinn IW, Romaguera JE, Hagemeister F, Dang NH, Fiumara P, Loyer EM, Cabanillas FF, McLaughlin PW, Rodriguez MA, Samaniego F: Phase II clinical trial of interleukin-12 in patients with relapsed and refractory non-Hodgkin's lymphoma and Hodgkin's disease. Clin Cancer Res 2004, 10(16):5432-8.

37. Wadler S, Levy D, Frederickson HL, Falkson Cl, Wang Y, Weller E, Burk R, Ho G, Kadish AS, Eastern Cooperative Oncology Group: A phase II trial of interleukin-12 in patients with advanced cervical cancer: clinical and immunologic correlates. Eastern Cooperative Oncology Group study E1E96. Gynecol Oncol 2004, 92(3):957-64.

38. Brode S, Raine T, Cooke A: Cyclophosphamide-Induced Type-1 Diabetes in the NOD Mouse Is Associated with a Reduction of $\mathrm{CD} 4^{+} \mathrm{CD} 25^{+} \mathrm{Foxp}^{+}$ Regulatory T Cells. The Journal of Immunology 2006, 177:6603-6612.

39. Di Paolo Nelson C, Tuve S, Ni S, Hellström KE, Hellström I, Lieber A: Effect of Adenovirus-Mediated Heat Shock Protein Expression and Oncolysis in Combination with Low-Dose Cyclophosphamide Treatment on Antitumor Immune Responses Cancer Research. 2006, 66:960-969.

40. Taieb J, Chaput N, Schartz N, Roux S, Novault S, Ménard C, Ghiringhelli F, Terme M, Carpentier AF, Darrasse-Jèze G, Lemonnier F, Zitvogel L: Chemoimmunotherapy of tumors: cyclophosphamide synergizes with exosome based vaccines. J Immunol 2006, 176(5):2722-9.
41. Morini M, Albini A, Lorusso G, Moelling K, Lu B, Cilli M, Ferrini S, Noonan DM: Prevention of angiogenesis by naked DNA IL-12 gene transfer: angioprevention by immunogene therapy. Gene Therapy 2004, 11(3):284-291.

42. Motoyoshi Y, Kaminoda K, Saitoh O: Different mechanisms for anti-tumor effects of low- and high-dose cyclophosphamide. Oncol Rep 2006, 16(1):141-6.

43. François G, Nicolas L, Elise S, Parcellier A, Dominique C, Carmen G, Bruno C, François M: CD4+CD25+ regulatory T cells suppress tumor immunity but are sensitive to cyclophosphamide which allows immunotherapy of established tumors to be curative. Eur J Immunol 2004, 34(2):336-44

44. Salem ML, Kadima AN, EL-Naggar SA, et al: Defining the ability of cytophosphamide preconditioning to enhance the antigen-specific CD8 + T-cell response to peptide vaccination: Creation of a beneficial host microenvironment involving type 1 IFNs and myeloid cells. J Immunother 2007, 30(1):40-53.

45. Breloer M, Dorner B, More SH: Heat shock proteins as "danger signals": eukaryotic Hsp60 enhances and accelerates antigen-specific IFN-gamma production in T cells. Eur J Immunol 2001, 31(7):2051-9.

46. Castelli RL, Carrabba C, Mazzaferro M, Pilla V, Huber L, Coppa V, Parmiani J, Giorgio P: Human tumor-derived heat shock protein 96 mediates in vitro activation and in vivo expansion of melanoma- and colon carcinomaspecific T cells. J Immunol 2003, 171(7):3467-74.

47. More $\mathrm{SH}$, Breloer $\mathrm{M}$, von Bonin $\mathrm{A}$ : Eukaryotic heat shock proteins as molecular links in innate and adaptive immune responses: Hsp60mediated activation of cytotoxic T cells. Int Immunol 2001, 13(9):1121-721.

48. Nowak AK, Lake RA, Bruce WS, Robinson : Combined chemoimmunotherapy of solid tumours: Improving vaccines? Advanced Drug Delivery Reviews 2006, 58(8):975-99034.

49. Berinstein NL: Enhancing cancer vaccines with immunomodulators. Vaccine 2007, 25s:b72-b88.

\section{doi:10.1186/1756-9966-30-24}

Cite this article as: Guo et al: Antitumor activity of mixed heat shock protein/peptide vaccine and cyclophosphamide plus interleukin-12 in mice sarcoma. Journal of Experimental \& Clinical Cancer Research 2011 30:24.

\section{Submit your next manuscript to BioMed Central and take full advantage of:}

- Convenient online submission

- Thorough peer review

- No space constraints or color figure charges

- Immediate publication on acceptance

- Inclusion in PubMed, CAS, Scopus and Google Scholar

- Research which is freely available for redistribution 